\title{
Chondroitin Sulfate A Is a Cell Surface Receptor for Plasmodium falciparum-infected Erythrocytes
}

\author{
By Stephen J. Rogerson, Sansanee C. Chaiyaroj, Ken Ng, \\ John C. Reeder, and Graham V. Brown
}

From The Walter and Eliza Hall Institute of Medical Research, Victoria 3050, Australia

\begin{abstract}
Summary
Adherence of Plasmodium falciparum-infected erythrocytes to cerebral postcapillary venular endothelium is believed to be a critical step in the development of cerebral malaria. Some of the possible receptors mediating adherence have been identified, but the process of adherence in vivo is poorly understood. We investigated the role of carbohydrate ligands in adherence, and we identified chondroitin sulfate (CS) as a specific receptor for $P$. falciparum-infected erythrocytes. Parasitized cells bound to Chinese hamster ovary (CHO) cells and $\mathrm{C} 32$ melanoma cells in a chondroitin sulfate-dependent manner, whereas glycosylation mutants lacking chondroitin sulfate A (CSA) supported little or no binding. Chondroitinase treatment of wild-type $\mathrm{CHO}$ cells reduced binding by up to $90 \%$. Soluble CSA inhibited binding to CHO cells by $99.2 \pm 0.2 \%$ at $10 \mathrm{mg} / \mathrm{ml}$ and by $72.5 \pm 3.8 \%$ at $1 \mathrm{mg} / \mathrm{ml}$, whereas a range of other glycosaminoglycans such as heparan sulfate had no effect. Parasite lines selected for increased binding to CHO cells and most patient isolates bound specifically to immobilized CSA. We conclude that $P$. falcipanum can express or expose proteins at the surface of the infected erythrocyte that mediate specific binding to CSA. This mechanism of adherence may contribute to the pathogenesis of $P$. falciparum malaria, but has wider implications as an example of an infectious agent with the capacity to bind specifically to cell-associated or immobilized CS.
\end{abstract}

$\mathrm{C}$ ytoadherence of Plasmodium falciparum-infected erythrocytes (IEs) ${ }^{1}$ to cerebral postcapillary venular endothelium is a striking feature of the pathology of cerebral malaria $(1,2)$. The phenomenon has been studied in vitro using cell lines such as human endothelial cells $(3,4)$ and C32 melanoma cells (5), and a variety of purified glycoprotein receptors. Thrombospondin (6), CD36 (7), intercellular adhesion molecule 1 (ICAM-1) (8), vascular cell adhesion molecule 1 , and E-selectin (9) have all been implicated as receptors on host cells, but the adherence patterns observed in some studies $(4,10,11)$ suggest that additional, as yet unidentified, receptors exist. Sulfated glycoconjugates, including the glycosaminoglycan (GAG) heparin, interfere with attachment of Plasmodium sporozoites to the hepatocyte surface and may decrease sporozoite infectivity in mice $(12,13)$.

We tested the hypothesis that GAGs may be involved in cell-cell interactions in asexual stages of $P$. falciparum and found that IEs bound to cell-associated chondroitin sulfate (CS) and to immobilized chondroitin sulfate A (CSA) and that binding was inhibited by hydrolysis of cell surface CS, or by free CSA.

1 Abbreviations used in this paper: $\mathrm{CHO}$, Chinese hamster ovary; $\mathrm{CS}$, chondroitin sulfate; CSA, CSB, and CSC, chondroitin sulfates A, B, and C, respectively; GAG, glycosaminoglycan; HS, heparan sulfate; HUVEC, human umbilical vein endothelial cell; ICAM-1, intercellular adhesion molecule 1; IE, infected erythrocyte; PE, dipalmitoylphosphatidylethanolamine; TM, thrombomodulin.

\section{Materials and Methods}

Chemicals. Heparin (porcine intestinal mucosa), heparan sulfate (HS) (bovine kidney), dextran sulfate, fucoidan, CSA (porcine rib cartilage), chondroitin sulfate $\mathrm{B}$ (CSB) (bovine mucosa), chondroitin sulfate C (CSC) (shark cartilage), chondroitinase ABC (from Proteus vulgaris), heparitinase (from Flawobacterium heparinum), chymotrypsin, and pronase were from Sigma Chemical Co. (Sydney, Australia), and L-1-tosylamido-2-phenylchloromethyl ketone-treated trypsin (trypsin-TPCK) was from Worthington Biochemical Corp. (Freehold, NJ).

Parasitized Erythrocytes. Parasite strains FAF-EA8, D7, and E10 were derived from the Brazilian isolate ItG2F6. FAF-EA8 was cloned and selected on endothelial cells $(10,14)$, and D7 and E10 were cloned and selected for rosetting. FAF-EA8CHO5 was selected five times on Chinese hamster ovary (CHO) cells and D7CHO6 and E10CHO6 were selected six times, as will be described. Primary isolates A-F were from children living in Madang, Papua New Guinea (provided by Dr. F. Al-Yaman, Papua New Guinea Institute of Medical Research). Primary isolates G-I were from Australian travellers who had acquired malaria in various countries. Parasites were cultured as previously described (15), but using $5 \%$ human serum. Cultures were synchronized every 1-2 wk by sorbitol lysis (16).

Cell Lines. Wild-type (K1) $\mathrm{CHO}$ cells and $\mathrm{CHO}$ cell glycosylation mutants (gifts of Prof. Jeffrey D. Esko, University of Alabama at Birmingham, Birmingham, $\mathrm{AL}$ ) and C32 amelanotic melanoma cells (ATTC CRL 1585; American Type Culture Collection, Rockville, $\mathrm{MD})$ were cultured and plated as described $(3,5,17)$. 
All cells were used unfixed. CHO cell glycosylation mutant 677 expresses no HS, with a compensatory increase in CS, and mutant 745 expresses neither HS nor CS (18).

Purified Ligands. Platelet-derived CD36 (7) (Dr. M. Berndt, Baker Institute, Melbourne, Australia) was used at $1 \mu \mathrm{g} / \mathrm{ml}$, and recombinant soluble ICAM-1 (Dr. A. Boyd, The Walter and Eliza Hall Institute of Medical Research, Melbourne, Australia) was used at $10 \mu \mathrm{g} / \mathrm{ml}$. Duplicate spots of CD36 or ICAM-1 (40 $\mu$ l for laboratory strains; $10 \mu \mathrm{l}$ for wild-type isolates) were adsorbed overnight onto 36-mm petri dishes, blocked with $1 \% \mathrm{BSA}$, and washed with RPMI-Hepes (MultiCel; Cytosystems, Castle Hill, Australia) before assays.

Cytoadherence Assays, Inhibition of Binding by GAGs, and Erythrocyte Rosette Formation. Assays were performed at 3-7\% parasitemia and $2 \%$ hematocrit in RPMI-Hepes supplemented with $10 \%$ serum. IEs were incubated with purified ligands or cells for $1 \mathrm{~h}$ at $37^{\circ} \mathrm{C}$ before nonadherent cells were washed off with RPMI-Hepes. To assess binding, dishes were fixed with $2 \%$ glutaraldehyde, stained with Giemsa, and examined microscopically. At least $300 \mathrm{CHO}$ cells or 500 adherent IEs were counted. GAGs and other glycoconjugates were tested for inhibition of binding by adding them to the parasite culture (at a final concentration of $10 \mu \mathrm{g} / \mathrm{ml}$ ) immediately before the assay. Rosetting assays were performed as previously described (19).

Selection for Increased CHO Cell Binding. To select for increased CHO cell binding, after removal of nonadherent cells in the assay described, the adherent cells were incubated with fresh culture medium and erythrocytes. The next day, after trophozoite maturation, division, and reinvasion, ring IEs were transferred to a new dish. To prevent the introduction of viable $\mathrm{CHO}$ cells into the ongoing culture, CHO cells were irradiated (3,000 rads) immediately before use.

Enzyme Treatment of CHO Cells and of IEs. $\mathrm{K} 1 \mathrm{CHO}$ cells were incubated with chondroitinase ABC (which cleaves linkages in CSA, $\mathrm{CSB}$, and CSC) or heparitinase (which specifically cleaves $\mathrm{HS}$ chains) in RPMI-Hepes for $45 \mathrm{~min}$ at $37^{\circ} \mathrm{C}$ and then washed three times with RPMI-Hepes. For protease treatment of erythrocytes, the FAFEA8CHO5 culture was washed once in RPMI-Hepes and suspended at $3 \%$ hematocrit in $100 \mu \mathrm{g} / \mathrm{ml}$ protease at $37^{\circ} \mathrm{C}$ for $30 \mathrm{~min}$. The reaction was quenched with $10 \%$ human serum, and cells were washed three times with PBS before the binding assay.

$G A G$ Conjugates. CSA and heparin were linked to dipalmitoylphosphatidylethanolamine (PE) through the reducing terminus, using the method of Sugiura et al. (20). Concentration of PE-linked material was determined by hexuronic acid assay. PE-linked CSA (CSA-PE) was used at a concentration of $50 \mu \mathrm{g} / \mathrm{ml}$, and heparin$\mathrm{PE}$ was used at $260 \mu \mathrm{g} / \mathrm{ml}$. Duplicate $25-\mu \mathrm{l}$ spots $(10 \mu \mathrm{l}$ for primary isolates) were adsorbed onto petri dishes overnight and blocked for $30 \mathrm{~min}$ with $1 \%$ BSA. Adherence assays were performed and counted as previously described. For prevention of adherence, CSA or HS was added to parasitized cells at $10 \mu \mathrm{g} / \mathrm{ml}$ immediately before the assay.

\section{Results}

Selection for Binding to CHO Cells Selects for Binding to CS and Alters Adherence to Other Ligands. The three parasite lines were selected for increased binding to CHO cells. CS normally forms $\sim 30 \%$ of GAG on the cell surface. Binding of the selected line FAF-EA8CHO5 was completely dependent on the presence of cell surface CS. IEs bound well to CHO cell mutant 677 , which expressed excess CS and no HS, but adhesion to $745 \mathrm{CHO}$ cells (with neither HS nor CS) was absent (Table 1). The binding of the selected lines D7CHO6 and E10CHO6 was mainly, but not completely, attributable to CS (Table 1).

Selection for binding to $\mathrm{CHO}$ cells altered the adherence profile to other ligands. Binding to ICAM-1 and CD36 decreased markedly, by $>95 \%$ for parasite line FAF-EA 8 (Table 1). Adherence to $C 32$ melanoma cells increased and became more readily inhibited by CSA (Table 1), in keeping with the observation that between 2 and $11 \mathrm{CS}$ chains are attached to a $250-\mathrm{kD}$ surface proteoglycan of melanoma cells (21).

Free CSA Inhibits and Reverses Binding to CHO Cells. The CSA used (from porcine rib cartilage) is composed of predominantly 4-sulfated $\mathrm{N}$-acetylgalactosamine and approximately equal amounts of glucuronic acid and iduronic acid (22). CSA significantly impaired binding of FAF-EA8CHO5

Table 1. Binding of Infected Erythrocytes to Cells and Purified Ligands

Cells and purified ligands tested

\begin{tabular}{lcccccccc}
\cline { 2 - 6 } Line & K1 CHO & 677 CHO & 745 CHO & HUVEC & C32 & $\begin{array}{c}\text { C32 + CSA binding } \\
\text { (inhibition \%) }\end{array}$ & CD36 & ICAM-1 \\
\hline FAF-EA8 & $82 \pm 12$ & ND & ND & $692 \pm 60$ & $1,133 \pm 37$ & $968 \pm 45(14.6 \%)$ & $1,253 \pm 262$ & $642 \pm 106$ \\
FAF-EA8 & & & & & & & & \\
CHO5 & $585 \pm 29$ & $2,215 \pm 491$ & $2 \pm 1$ & $17 \pm 9$ & $2,149 \pm 362$ & $80 \pm 25(96.3 \%)$ & $59 \pm 9$ & $6 \pm 2$ \\
E10 & $13 \pm 2$ & ND & ND & $221 \pm 63$ & $227 \pm 15$ & $176 \pm 48(22.5 \%)$ & ND & $184 \pm 41$ \\
E10CHO6 & $430 \pm 36$ & $1,344 \pm 193$ & $149 \pm 9$ & $53 \pm 6$ & $1,285 \pm 33$ & $370 \pm 77(71.2 \%)$ & $324 \pm 80$ & $100 \pm 11$ \\
D7 & $40 \pm 8$ & ND & ND & $665 \pm 112$ & $559 \pm 88$ & $466 \pm 96(16.6 \%)$ & $501 \pm 95$ & $76 \pm 6$ \\
D7CHO6 & $635 \pm 91$ & $1,740 \pm 344$ & $84 \pm 8$ & $220 \pm 39$ & $1,605 \pm 159$ & $671 \pm 147(58.2 \%)$ & $142 \pm 16$ & $73 \pm 18$ \\
\hline
\end{tabular}

Comparison of selected lines and parent lines for adherence to wild-type CHO cells, CHO glycosylation mutants 677 and 745, CD36, ICAM-1, human umbilical vein epithelial cells (HUVECs), and C32. Values are mean \pm SE binding for triplicate experiments. Binding to cells is per 100 cells; binding to purified ligands is per square millimeter. 


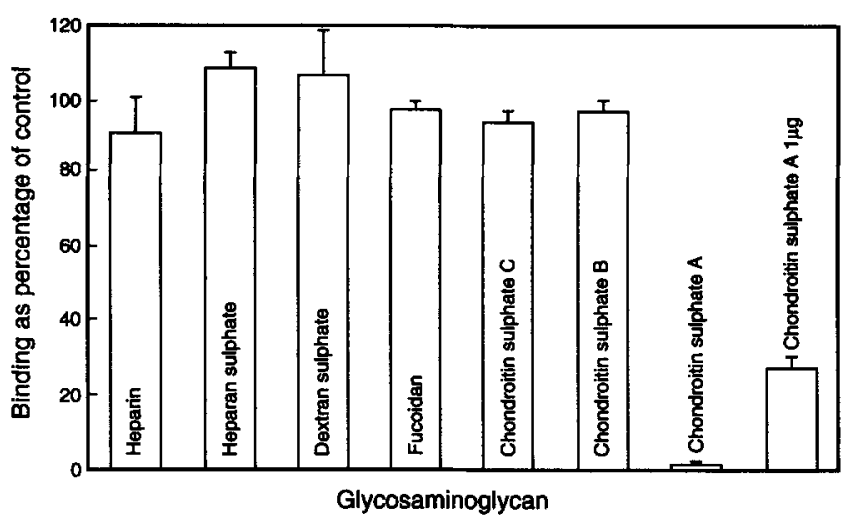

Figure 1. Inhibition of binding of FAF-EA8CHO5 to K1 CHO cells by GAGs and glycoconjugates. All chemicals were added to binding assays at $10 \mu \mathrm{g} / \mathrm{ml}$; CSA was additionally used at $1 \mu \mathrm{g} / \mathrm{ml}$. Results show binding as a percentage of control, with mean $\pm \mathrm{SE}$ for triplicate experiments.

to $\mathrm{K} 1 \mathrm{CHO}$ cells at $10 \mu \mathrm{g} / \mathrm{ml}(99.2 \pm 0.2 \%)$ and $1 \mu \mathrm{g} / \mathrm{ml}$ $(72.5 \pm 3.8 \%)$. CSB contains $\sim 85 \%$ iduronic acid, and CSC consists of 6-sulfated $\mathrm{N}$-acetylgalactosamine and glucuronic acid. Neither inhibited binding at $10 \mu \mathrm{g} / \mathrm{ml}$ (Fig. 1). HS, the predominant $\mathrm{CHO}$ cell surface GAG, did not inhibit binding, even at $100 \mu \mathrm{g} / \mathrm{ml}$. Free CSA had no effect on binding to ICAM-1 or CD36 (data not shown). Addition of free CSA at time points during an adherence assay substantially reversed cytoadherence. Free CSA $(10 \mu \mathrm{g} / \mathrm{ml})$ added $15 \mathrm{~min}$ before completion of a binding assay released $>80 \%$ of bound parasites (data not shown).

Treatment of CHO Cells with Chondroitinase or IEs with Protease but Not Trypsin Reduces Cytoadherence. Treatment of $\mathrm{CHO}$ cells with chondroitinase ABC markedly reduced binding, but heparitinase had no effect (Fig. 2). Treatment of IEs with chondroitinase or heparitinase did not alter binding (data not shown). Trypsin treatment of the IEs had no effect on binding to CHO cells, whereas both chymotrypsin and pronase reduced adherence (Fig. 2), suggesting that a trypsinresistant protein mediates adherence to CSA on CHO cells.

Binding to Immobilized CSA. CSA and heparin were conjugated to PE to allow immobilization of GAG on polystyrene plates. Parental strains bound to CSA-PE, and binding

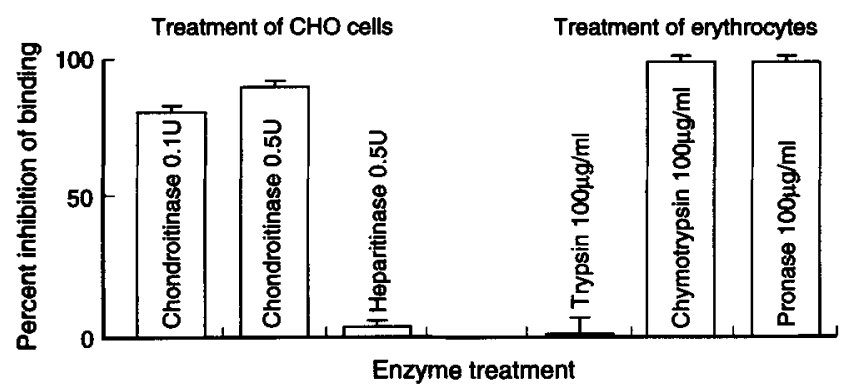

Figure 2. Effect of glycosidase treatment of $\mathrm{CHO}$ cells and protease treatment of IEs on cytoadherence. Results show the percent decrease in binding $( \pm S E)$ compared with control for triplicate experiments.

was increased in selected lines (Table 2), but there was no significant binding to heparin-PE. Binding was almost totally inhibited by free CSA, but HS had no effect (Table 2).

Patient Isolates May Bind to Immobilized CSA. Five of nine primary isolates tested bound to CSA-PE (Table 3), suggesting that this phenomenon is likely to be of biological relevance in natural infections. The isolates were also examined for rosette formation and for binding to CD 36 , ICAM-1, and CSA. All formed rosettes and adhered to CD36, and six adhered to ICAM-1 at $>5 / \mathrm{mm}^{2}$ (Table 3). In this small study, there was no correlation between CSA binding and other phenotypic characteristics. Although levels of CSA binding were modest, isolate $\mathrm{F}$ was successfully adapted to in vitro culture and then underwent three rounds of selection on CSA-PE. This selected line bound very well to CSA-PE $>2,000$ IEs per $\mathrm{mm}^{2}$ ).

\section{Discussion}

Several infectious agents are known to adhere to HS (23-25), and proteoglycans containing $\mathrm{HS}$ are widely distributed on vascular endothelium (26). The intravascular distribution of CS proteoglycans has not been well studied, and to our knowledge, binding of infectious agents to CS has not been previously described.

Variation in expression of CS on endothelia in sites of parasite sequestration could represent a host factor in malaria patho-

Table 2. Binding of Infected Erythrocytes to Immobilized Glycosaminoglycans

\begin{tabular}{lccrr}
\hline Line & CSA-PE & Heparin-PE & CSA-PE + CSA & CSA-PE + HS \\
\hline FAF-EA8 & $90 \pm 9$ & $0.5 \pm 0.2$ & $0.8 \pm 0.3$ & $105 \pm 9$ \\
FAF-EA8CHO5 & $2,350 \pm 269$ & $7 \pm 4$ & $0.25 \pm 0.2$ & $2,488 \pm 143$ \\
E10 & $32 \pm 6$ & $0.5 \pm 0.2$ & $0.7 \pm 0.4$ & $39 \pm 7$ \\
E10CHO6 & $987 \pm 108$ & $0.7 \pm 0.5$ & $0.7 \pm 0.5$ & $1,033 \pm 83$ \\
D7 & $36 \pm 8$ & $0.5 \pm 0.2$ & $0.1 \pm 0.1$ & ND \\
D7CHO6 & $3,400 \pm 187$ & $0 \pm 0$ & $0.9 \pm 0.5$ & $3,091 \pm 199$
\end{tabular}

Adherence of IEs to CSA-PE or heparin-PE and to CSA-PE in the presence of free CSA or HS (10 $\mu \mathrm{g} / \mathrm{ml})$. Results are expressed as parasites bound per $\mathrm{mm}^{2}$ and show mean $\pm \mathrm{SE}$ for triplicate experiments. 
Table 3. Binding of Patient Isolates to Purified Ligands and to Uninfected Erythrocytes (Rosetting)

\begin{tabular}{lcclll}
\hline Isolate & Parasitemia & Rosetting & CD36 & ICAM-1 & \multicolumn{1}{c}{ CSA-PE } \\
\hline A & $1.0 \%$ & $1 \%$ & 69,93 & 54,36 & $0,0,0,1$ \\
B & $0.9 \%$ & $0.7 \%$ & 334,337 & 4,4 & $12,10,12,12$ \\
C & $1.3 \%$ & $1.7 \%$ & 335,347 & 3,5 & $0,1,4,1$ \\
D & $0.7 \%$ & $4.5 \%$ & 288,309 & 2,2 & $2,1,0,0$ \\
E & $1.6 \%$ & $1.7 \%$ & 541,192 & 37,16 & $8,5,6,13$ \\
F & $13.0 \%$ & $7.5 \%$ & $3780, \mathrm{ND}$ & 83,122 & $55,50,32,82$ \\
G & $11.2 \%$ & $5.9 \%$ & 3540,2995 & 21,44 & $8,8,23,6$ \\
H & $3.8 \%$ & $15 \%$ & 2385,2267 & 327,255 & $8,24,27$ \\
I & $2.2 \%$ & $1.7 \%$ & 469,524 & 16,14 & $0,1,0,0$ \\
\hline
\end{tabular}

Patient isolates were tested for rosette formation and for binding to CD36, ICAM-1, and CSA-PE. Binding is expressed as parasites bound per square millimeter for duplicate assays (each of two spots for CSA-PE), and rosetting is given as the percentage of trophozoite-IEs in rosettes. Parasitemias represent the percentage of all erythrocytes infected with trophozoites at the time of assay.

genesis. One or more CS chains can be linked to thrombomodulin (TM) (27), an integral membrane protein of vascular endothelium. These chains, composed predominantly of CSA, have functional activity in thrombin-TM interactions. CS may also be attached to the endothelial proteoglycan ryudocan in the rat (28). We speculate that CSA attached to TM, or potentially to human ryudocan, may be involved in adhesion in vivo. Our preliminary data (Rogerson, S. J., unpublished observations) show that HUVECs from some but not all individual donors have detectable surface CSA. This agrees with the observations of Lin et al. (29) that HUVECs from pooled donors contain less TM, and a lower proportion of TM that has CS attached, than arterial endothelial cells from a single donor. The expression of other receptors that mediate adherence of IEs to endothelium has recently been shown to correlate with patterns of sequestration (30), but the distribution of CSA on microvascular endothelium representing preferred sites of sequestration was not examined by Lin et al. (29).

We have recently described trypsin-resistant adherence to C32 melanoma cells of a parasite line, T4, that has a trypsinresistant, chyomotrypsin-sensitive, high molecular weight protein detectable by surface radioiodination (10). Binding of T4 to C32 melanoma cells was reduced by free CSA (Chaiyaroj, S. C., unpublished observations). As with the CHO-selected lines, T4 binds less effectively than the parent FAF-EA8 to CD36 and ICAM-1. We postulated that this trypsin-resistant ligand on IEs mediates adherence (10), and we now believe that it may be interacting with CSA as receptor on the melanoma cell surface. It is unclear whether this represents a variant form of the putative cytoadherence molecule $P$. falciparum erythrocyte membrane protein 1 (31), but multiple ligands on the IEs are thought to mediate endothelial cell adherence in vitro (32), and more than one may be expressed simultaneously (10).

Our finding that primary isolates and laboratory strains of $P$. falciparum adhere to CSA may explain the previously observed adherence of parasite line FC27 to an unidentified ligand on microvascular endothelial cells (4), and it is consistent with the observations of Hasler et al. (11) that one of five Malawian isolates bound at significant levels to wild-type CHO cells. These data suggest that ICAM-1 and CD36 transfected CHO cells (11) may not be appropriate substitutes for the immobilized ligands in assessing adherence, as the contribution of CSA binding cannot readily be determined. Although binding of primary isolates was modest, in vitro selection increased this binding, and similar selection for adherence to CSA may operate in vivo.

The marked difference in inhibition of binding by CSA compared with CSB or CSC was surprising. The sulfation pattern and the proportions of glucuronic acid and its epimer iduronic acid in CS chains may be very variable (22). The porcine rib cartilage CSA used contains predominantly 4-sulfated $N$-acetylgalactosamine and approximately equal amounts of glucuronic acid and iduronic acid (22), whereas CSB contains a low proportion of glucuronic acid, and $N$-acetylgalactosamine residues in CSC are predominantly 6-sulfated. Although the current study did not elucidate the specific oligosaccharide motif that supports binding to the ligand on IEs, it appears to involve structures present in CSA that occur infrequently in the CSB or CSC preparations used. The relative involvement of glucuronic acid and iduronic acid in such a motif can be clarified only by studies using welldefined oligosaccharides.

The novel finding that CSA may act as a specific receptor for an infectious agent is of general interest, expanding the established roles of GAGs in cell-cell interactions. The discovery that CSA can be an adherence ligand for asexual stages of $P$. falciparum adds an extra level of complexity to attempts to unravel the interplay of IEs and host adhesion molecules and their relevance to the pathogenesis of severe malaria. These data suggest that malarial cytoadherence, like leukocyte adhesion, may involve both glycoprotein and carbohydrate receptors and offer a new approach to investigate the relationship between adherence and disease severity that has proved so elusive. 
Human serum and group O erythrocytes were kindly provided by the Red Cross Blood Bank (Victoria, Australia). S. J. Rogerson is the recipient of a National Health and Medical Research Council of Australia (NHMRC) Medical Postgraduate Research Scholarship, and S. C. Chaiyaroj is the recipient of a World Health Organization/Tropical Diseases Research Postdoctoral Training Fellowship. The work of the Immunoparasitology Unit has been supported by the John D. and Catherine T. MacArthur Foundation, the NHMRC and Saramane Pty Ltd., a joint venture with Hoffmann-La Roche.

Address correspondence to Dr. Stephen J. Rogerson, The Walter and Eliza Hall Institute of Medical Research, Post Office Royal Melbourne Hospital, Victoria 3050, Australia. Sansanee C. Chaiyaroj's present address is the Department of Microbiology, Faculty of Science, Mahidol University, Bangkok 10400, Thailand.

Received for publication 11 October 1994 and in revised form 21 February 1995.

\section{References}

1. Aikawa, M., M. Iseki, J.W. Barnwell, D. Taylor, M.M. Oo, and R.J. Howard. 1990. The pathology of human cerebral malaria. Am. J. Trop. Med. Hyg. 43:30-37.

2. Warrell, D.A., M.E. Molyneux, and P.F. Beales. 1990. Severe and complicated malaria. Trans. Roy. Soc. Trop. Med. Hyg. 84:1-65.

3. Udeinya, I.J., J.A. Schmidt, M. Aikawa, L.H. Miller, and I. Green. 1981. Falciparum malaria-infected erythrocytes specifically bind to cultured human endothelial cells. Science (Wash. DC). 213:555-557.

4. Johnson, J.K., R.A. Swerlick, K.K. Grady, P. Millet, and T.M. Wick. 1993. Cytoadherence of Plasmodium falcipanum-infected erythrocytes to microvascular endothelium is regulatable by cytokines and phorbol ester. J. Infect. Dis. 167:698-703.

5. Schmidt, J.A., I.J. Udeinya, J.H. Leech, R.J. Hay, M. Aikawa, J. Barnwell, I. Green, and L.H. Miller. 1982. Plasmodium falciparum malaria. An amelanotic melanoma cell line bears receptors for the knob ligand on infected erythrocytes. J. Clin. Invest. 70:379-386.

6. Roberts, D.D., J.A. Sherwood, S.L. Spitalnik, L.J. Panton, R.J. Howard, V.M. Dixit, W.A. Frazier, L.H. Miller, and V. Ginsburg. 1985. Thrombospondin binds Falciparum malaria parasitized erythrocytes and may mediate cytoadherence. Nature (Lond.). 318:64-66.

7. Ockenhouse, C.F., N.N. Tandon, C. Magowan, G.A. Jamieson, and J.D. Chulay. 1989. Identification of a platelet membrane glycoprotein as a Falciparum malaria sequestration receptor. Science (Wash. DC). 243:1469-1471.

8. Berendt, A.R., D.L. Simmons, J. Tansey, C.I. Newbold, and K. Marsh. 1989. Intercellular adhesion molecule 1 is an endothelial cell adhesion molecule for Plasmodium falciparum. Nature (Lond.). 341:57-59.

9. Ockenhouse, C.F., T. Tegoshi, Y. Maeno, C. Benjamin, M. Ho, K.E. Kan, Y. Thway, K. Win, M. Aikawa, and R.R. Lobb. 1992. Human vascular endothelial cell adhesion receptors for Plasmodium falciparum-infected erythrocytes: roles for endothelial leukocyte adhesion molecule 1 and vascular cell adhesion molecule 1. J. Exp. Med. 176:1183-1189.

10. Chaiyaroj, S.C., R.L. Coppel, S. Novakovic, and G.V. Brown. 1994. Multiple ligands for cytoadherence are present on the surface of Plasmodium falciparum infected erythrocytes. Proc. Natl. Acad. Sci. USA. 91:10805-10808.

11. Hasler, T., G.R. Albrecht, M.R. van Schravendijk, J.C. Aguiar, K.E. Morehead, B.L. Pasloske, C. Ma, J.W. Barnwell, B. Greenwood, and R.J. Howard. 1993. An improved microassay for Plasmodium falciparum cytoadherence using stable transformants of Chinese hamster ovary cells expressing CD36 or intercel- lular adhesion molecule-1. Am. J. Trop. Med. Hyg. 48:332-347. 12. Pancake, S.J., and M.R. Hollingdale. 1986. Plasmodium berghei: reaction of sporozoites with chemically and enzymatically modified hepatoma cells. Exp. Parasitol. 62:120-126.

13. Cerami, C., U. Frevert, P. Sinnis, B. Takacs, P. Clavijo, M.J. Santos, and V. Nussenzweig. 1992. The basolateral domain of the hepatocyte plasma membrane bears receptors for the circumsporozoite protein of Plasmodium falciparum sporozoites. Cell. 70:1021-1033.

14. Biggs, B.A., L. Goozé, K. Wycherley, W. Wollish, B. Southwell, J.H. Leech, and G.V. Brown. 1991. Antigenic variation in Plasmodium falciparum. Proc. Natl. Acad. Sci. USA. 88:91719174.

15. Trager, W., and J. Jensen. 1976. Human malaria parasites in continuous culture. Science (Wash. DC). 193:673-675.

16. Lambros, C., and J.P. Vanderberg. 1979. Synchronization of Plasmodium falciparum erythrocytic stages in culture. J. Parasitol. 65:418-420.

17. Esko, J.D., T.E. Stewart, and W.H. Taylor. 1985. Animal cell mutants defective in glycosaminoglycan biosynthesis. Proc. Natl. Acad. Sci. USA. 82:3197-3201.

18. Esko, J.D. 1991. Genetic analysis of proteoglycan structure, function and metabolism. Curr. Opin. Cell Biol. 3:805-816.

19. Rogerson, S.J., J.C. Reeder, F. Al-Yaman, and G.V. Brown. 1994. Sulfated glycoconjugates as disrupters of Plasmodium falciparum erythrocyte rosettes. Am. J. Trop Med. Hyg. 51:198-203.

20. Sugiura, N., K. Sakurai, Y. Hori, K. Karasawa, S. Suzuki, and K. Kimata. 1993. Preparation of lipid-derivatized glycosaminoglycans to probe a regulatory function of the carbohydrate moieties of proteoglycans in cell-matrix interaction. J. Biol. Chem. 268:15779-15787.

21. Bumol, T.F., L.E. Walker, and R.A. Reisfeld. 1984. Biosynthetic studies of proteoglycans in human melanoma cells with a monoclonal antibody to a core glycoprotein of chondroitin sulfate proteoglycans. J. Biol. Chem. 259:12733-12741.

22. Karamanos, N.K., A. Syrokou, P. Vanky, M. Nurminen, and A. Hjerpe. 1994. Determination of 24 variously sulfated galactosaminoglycan- and hyaluronan-derived disaccharides by high-performance liquid chromatography. Anal. Biochem. 221:189-199.

23. Neyts, J., R. Snoeck, D. Schols, J. Balzarini, J.D. Esko, A. Van Schepdael, and E. De Clercq. 1992. Sulfated polymers inhibit the interaction of human cytomegalovirus with cell surface heparan sulfate. Virology. 189:48-58.

24. Frevert, U., P. Sinnis, C. Cerami, W. Shreffler, B. Takacs, and V. Nussenzweig. 1993. Malaria circumsporozoite binds to heparan sulfate proteoglycans associated with the surface mem- 
brane of hepatocytes. J. Exp. Med. 177:1287-1298.

25. Ortega-Barria, E., and M.E.A. Pereira. 1991. A novel T. cruzi heparin-binding protein promotes fibroblast adhesion and penetration of engineered bacteria and trypanosomes into mammalian cells. Cell. 67:411-421.

26. Ihrcke, N.S., L.E. Wrenshall, B.J. Lindman, and J.L. Platt. 1993. Role of heparan sulfate in immune system-blood vessel interactions. Immunol. Today. 14:500-505.

27. Gerlitz, B., T. Hassell, C.J. Vlahos, J.F. Parkinson, N.U. Bang, and B.W. Grinnell. 1993. Identification of the predominant glycosaminoglycan-attachment site in soluble recombinant human thrombomodulin: potential regulation of functionality by glycosyltransferase competition for serine ${ }^{474}$. Biochem. $J$. 295:131-140.

28. Shworak, N.W., M. Shirakawa, R.C. Mulligan, and R.D. Rosenberg. 1994. Characterization of ryudocan glycosaminoglycan acceptor sites. J. Biol. Chem. 269:21204-21214.

29. Lin, J:H., K. McLean, J. Morser, T.A. Young, R.M. Wydro,
W.H. Andrews, and D.R. Light. 1994. Modulation of glycosaminoglycan addition in naturally expressed and recombinant human thrombomodulin. J. Biol. Chem. 269:25021-25030.

30. Turner, G.D.H., H. Morrison, M. Jones, T.M.E. Davis, S Looareesuwan, I.D. Buley, K.C. Gatter, C.I. Newbold, S. Pukritayakamee, B. Nagachinta et al. 1994. An immunohistochemical study of the pathology of fatal malaria. Evidence for widespread endothelial activation and a potential role for intercellular adhesion molecule- 1 in cerebral sequestration. $\mathrm{Am}$. J. Pathol. 145:1057-1069.

31. Leech, J.H., J.W. Barnwell, L.H. Miller, and R.J. Howard. 1984. Identification of a strain-specific malarial antigen exposed on the surface of Plasmodium falciparum-infected erythrocytes. J. Exp. Med. 159:1567-1575.

32. Crandall, I., K.M. Land, and I.W. Sherman. 1994. Plasmodium falciparum: Pfalhesin and CD36 form an adhesin/receptor pair that is responsible for the $\mathrm{pH}$-dependent portion of cytoadherence/sequestration. Exp. Parasitol. 78:203-209. 